\title{
RACIONALIDADE RELIGIOSA E DEBATE PÚBLICO
}

\author{
[RELIGIOUS RATIONALITY AND PUBLIC DEBATE]
}

\begin{abstract}
Resumo: A filosofia da religião de Habermas defende que o Estado Democrático deve garantir a diversidade das cosmovisões originadas das múltiplas racionalidades que formam as sociedades atuais, promovendo o diálogo entre elas. Contudo, para que tal diálogo exista, se faz necessário o reconhecimento da racionalidade da argumentação exposta. Minha questão é que tipo de epistemologia é capaz de deferir que um pensamento surgido da fé religiosa possa ser incorporado à discussão pública? Esse artigo divide-se em quatro partes. Na primeira supero os desafios do cientificismo, na segunda avalio as tentativas teístas e busco uma epistemologia apropriada à religião, na terceira parto para o pragmatismo e na quarta esboço o tipo de pragmatismo que defendo. Nas considerações finais relato brevemente algumas consequências da presença da racionalidade religiosa como construtora de nosso tecido social.
\end{abstract}

Palavras-chave: Racionalidade; Religião; Pragmatismo
Irio Vieira Coutinho Abreu Gomes * Universidade Estadual da Paraíba, Brasil

\section{O Desafio do Cientificismo}

पá dois tipos de conhecimentos que confiamos com grande intensidade: a

1 evidência sensorial e o conhecimento lógico-matemático. A crença de que estou escrevendo esse texto agora é para mim tão segura quanto a crença de que $2+3=$ 5 , embora sejam de tipos diversos. Tanto os conhecimentos de razão (matemática e lógica) que geram verdades necessárias, quanto os de experiência (sensíveis e científicos) são considerados seguros e úteis por nós de diferentes maneiras.

O tipo de explicação com o maior poder de persuasão em nossos dias é a

* Professor do Departamento de filosofia da Universidade Estadual da Paraíba. E-mail: iriocoutinho@gmail.com 
explicação científica, sua força é tão grande que para muitos estudiosos e leigos ou uma explicação é científica ou não é uma explicação. Uma explicação científica é aquela que contém em seu corpo argumentativo apenas conectivos lógicos e leis científicas. Contudo, se defendo que "toda explicação deve ser científica" tenho uma tese problemática porque não é possível uma teoria científica que afirme que "toda explicação deva ser científica", posto que essa tese não é uma tese científica, mas filosófica. A contradição da frase "toda explicação possível é uma explicação científica" atesta que a ciência não pode se por como parâmetro da razão e quem o faz comete uma mera arbitrariedade.

A utilidade dos conhecimentos científicos nos leva a valorizá-los e a elaborar epistemologias diversas como aconteceu no século XVII nas disputas entre racionalismos e empirismos. Quando estudamos essa controvérsia no século XX notamos que a questão parece se complicar tanto pela fragilidade da diferença entre analítico e sintético (Quine) quanto pela elaboração de diferentes epistemologias para avaliar racionalmente o conhecimento científico a exemplo do falsificacionismo (Popper) que se apresenta como rival do confirmacionismo (Bunge). Enquanto o segundo endossa o conhecimento científico como aquele que é confirmado pela experiência, o primeiro afirma ser científico o conhecimento que pela experiência não foi refutado. Meu ponto aqui não é entrar na disputa entre os diferentes tipos de epistemologias de um mesmo tipo de conhecimento (o científico), mas o de que elaboramos epistemologias porque valorizamos tal conhecimento e essa valorização, de acordo com um pensamento de inspiração kantiana, passa pela suposta universalidade desse conhecimento.

Kant acreditava na universalidade da lógica e da matemática de uma maneira diferente da universalidade da Física, tanto que precisou inventar os juízos sintéticos $a$ priori para esclarecer essas nuances e socorrer a física de Newton do problema da indução de Hume. O esforço kantiano e depois o refinamento filosófico do círculo de Viena revelaram a dificuldade de encontrar uma epistemologia apropriada para a ciência, pois; como pode ser universal um conhecimento empírico?

Os trabalhos de Paul Feyerabend nos fizeram desacreditar da unicidade do método científico e os de Thomas Kuhn puseram em dúvida o realismo científico ou a identificação de que ciência e ontologia são o mesmo. O problema de Einstein com a mecânica quântica era um problema ontológico e não de teoria físico-matemática, a saber, a mecânica quântica nos entrega um mundo não-determinista o que para Einstein era um absurdo estampado em seu famoso "Deus não joga dados". Diante de tudo isso, a universalidade da ciência está longe de ser ponto pacífico entre os pesquisadores, mas nem por isso desacreditamos do conhecimento científico, tampouco desistimos de avaliar sua racionalidade com nossas epistemologias.

A ciência como única explicação da realidade e a universalidade da ciência são teses que não param em pé. Dessa maneira a crença religiosa e outras modalidades de crenças não-científicas, não podem ser descredenciadas do âmbito da racionalidade por não atenderem as exigências cientificistas. É claro que isso não é suficiente para chancelar a racionalidade da crença religiosa, mas abre as portas para sua possibilidade.

\section{As tentativas teístas}

Não sendo a universalidade um impeditivo para uma avaliação da racionalidade da ciência, não o será também para a religião e se a epistemologia da matemática é outra da epistemologia da ciência, há de se buscar uma epistemologia apropriada para a 
religião mostrando que diferentes tipos de conhecimento exigem diferentes tipos de epistemologias. Como enquadrar isso para o conhecimento religioso? A veracidade de uma proposição religiosa é comparável às outras duas (ciência e matemática)? De que maneira o conhecimento religioso poderia ser avaliado?

Os teístas dirão que a racionalidade da religião deriva da racionalidade do próprio Deus e isso é expresso nas provas de existência de Deus. A fé envolve algum tipo de conflito com a razão. Isso pode variar com o critério de razão e as tradições religiosas a que alguém esteja vinculado. Muitas vezes se tem fé contra as evidências, aceita-se pela autoridade alguma crença não mais evidente que outra. Mas é possível uma avaliação racional do religioso? É o teísmo o primeiro passo a ser dado?

Em geral esse projeto é desacreditado e o senso comum entende a opinião religiosa como estranha à ciência e à razão, concedendo-lhe uma espécie de prêmio de consolação, também dado à moralidade como algo íntimo, individual, fruto de algum tipo de sentimento ainda pouco estudado pela ciência ou escolhas arbitrárias influenciadas pelo ambiente cultural.

Contra aqueles que defendem o relativismo moral que acaba por ser o resultado da moralidade como algo íntimo, podemos refutá-los dizendo que precisamos decidir se possuir escravos, pedofilia e matar pessoas dependendo da razão é algo moral ou não, posto que leis devem ser formuladas a esse respeito temos de decidir objetivamente se essas ações são certas ou erradas. Para os teístas o mesmo se passa com as questões de religião, segundo Yandell:

Ou Deus existe ou não existe; ou o nirvana pode ser alcançado ou não pode. Se Deus existe ou é trino ou não é. Essas coisas são ou não são independente do que alguém pensa. Uma divindade omnicompetente, não menos que o planeta Plutão ou o time de futebol americano do Green Bay Packers, ou existe independente de nossos pensamentos ou não (YANDELL, 2002, p.344)

A diferença aqui é o tempo, posto que a decisão sobre alguns dilemas morais é urgente por afetar diretamente e de maneira muito evidente nossa rotina enquanto sociedade, já os filosofemas teístas parecem não incomodar muita gente e não têm, pelo menos no curto prazo, efeito.

As tentativas teístas destacam suas vantagens, quando em sendo verdadeiras, teríamos uma explicação de como acessar o mundo com nossa racionalidade, uma distinção entre bem e mal, autoconsciência moral e outros problemas. Para os teístas seus argumentos são verdadeiros se eles fornecem uma explicação de como isso tudo se obtém. A racionalidade do teísmo depende de como ele se sai perante seus competidores racionais, aqui o argumento tem sucesso se provar a racionalidade forte do teísmo em relação a seus concorrentes.

Plantinga explica que a epistemologia reformada toma a crença em Deus como uma crença básica. Sua principal justificativa é que não há qualquer bom argumento (leia-se não - circular) para tomar algo como uma crença básica (até a existência do mundo material cai na falácia da circularidade). Plantinga é um fundacionista radical sua diferença é apenas no tipo de fundação. Ele não nega o fundacionismo clássico ao modo de Descartes ou Hume, mas coloca que não encontra "um bom argumento" para se crer que determinada crença seja básica, como por exemplo, a existência de objetos materiais. Não é que Plantinga critique quem neles acredita, o problema não é acreditar que eles existam, mas em acreditar que existem razões definitivas que nos convençam que os mesmos existam. Da mesma forma, não haveria nenhum equívoco em ter Deus como uma crença básica.

O universo pode ser entendido e experimentado tanto de modo naturalista quanto 
religioso. É racional confiar em nossa experiência, exceto quando temos alguma razão para dela duvidar. Esse princípio é normalmente aplicado à experiência sensorial, sem a qual, não poderíamos nos mover no mundo e, por ser a religião de natureza diferente esse princípio a ela não se adequaria. Só para citar um exemplo a universalidade da experiência sensorial contrasta com a diversidade da vivência religiosa, claro que para críticas como essa há respostas como a condicionalidade da experiência religiosa ao ambiente cultural.

Para Plantinga nosso crer em algo como básico pode não estar sob nosso controle. Pode ainda acontecer que, após cuidadosa análise, pesquisa e reflexão, ou de uma fecunda "vida espiritual", acreditar em Deus seja algo óbvio para mim. Nessa esteira:

a crença em Deus deve ser propriamente uma crença básica no sentido de que se está perfeitamente justificado em sustentar essa crença como básica. De fato, não apenas isso é claro, isso é óbvio, e é difícil de ver como o evidencialista pode pensar de outro modo (PLANTINGA, p.677,2010).

Plantinga se lança numa espécie de internalismo com o objetivo de ter por verdadeira e justificada a crença em Deus. O critério básico está em ter para si que é verdade aquilo em que se crê. Após exame da estabilidade mental daquele que crê e de sua sinceridade no que crê aquela crença seria racional. Mas o que justificaria tal crença? Dentro dessa questão que remonta a Platão, Plantinga busca uma explicação para a palavra justificação (Warrant), seu argumento se assenta numa relação implícita entre a justificativa e as propriedades mentais que a produziram.

Nesse ponto, Plantinga parece estar à beira de algum tipo de solipsismo ou de epistemologia do homem solitário, pois não enxergo como tal crença deva ser aceita por outros que não compartilham com o mesmo tipo de experiência interior. Além disso, há dois problemas que Plantinga tem de resolver, o primeiro é que não é porque não há bons argumentos (não-circular) para defender que "existem objetos materiais" como crença básica que podemos aceitar Deus como crença básica (aqui a falácia é gritante). Mas se supomos que mudamos o critério e não aceitemos mais o rigor dos modernos, Plantinga ainda teria de nos dizer o que justifica tomar algo como crença básica, pois se crer firmemente e sinceramente em algo pode se por como crença básica, qualquer coisa poderia ser uma crença básica.

Yandell (2002, p.356) apresenta a argumentação monoteísta como segue:

M1 - O monoteísmo tem poder explicativo sobre coisas que dificilmente seriam explicadas de outra forma.

M2 - O monoteísmo não foi falsificado.

M3 - O monoteísmo possui evidência experiencial de eventos que só podem existir se o monoteísmo também existir.

M4 - Se M1, M2 e M3, então há evidência que o monoteísmo é verdadeiro.

Conclusão

M5 - Há evidências que o monoteísmo é verdadeiro.

Muito bem. Se o argumento quer apenas mostrar que o teísmo é racional em explicar algumas coisas, mas que essa sua racionalidade não nega o oposto, não vejo problemas (desde Kant) nesse teísmo. Por outro lado, se o argumento reclama uma exclusividade explicativa, não aceitando a racionalidade do argumento de oposição, o teísta teria de pagar o preço de provar o erro do raciocínio ateu. Nesse quesito a crítica kantiana é insuperável. Não vou entrar na discussão entre teístas e ateísta, apenas fazer alguma pontuação. Voltemos ao esquema de Yandell:

M1 afirma que: "O monoteísmo tem poder explicativo sobre coisas que 
dificilmente seriam explicadas de outra forma", dizer que o movimento é explicado por um motor imóvel implica ter de explicar o próprio motor imóvel, posso pensar que o movimento sempre existiu.

M2 afirma que: "O monoteísmo não foi falsificado", a tese da eternidade do universo também não foi falsificada.

M3 afirma que: "O monoteísmo possui evidencia experiencial de eventos que só podem existir se o monoteísmo também existir”. O monoteísmo tem, no máximo, uma argumentação (sempre contestada pelo ateísmo) de que alguns eventos só podem existir se o monoteísmo existir. Uma "evidência experiencial" indica uma experiência que não existiria se Deus não existisse, para tanto Deus deveria ser a razão da existência de tal coisa, mas algo para existir não tem de necessariamente ter sido criado (o universo é o melhor exemplo).

Contra o teísmo se levanta o verificacionismo que não aceita a existência de entidades não observáveis. Os teístas tomam sua defesa dizendo que isso leva a problemas mesmo para a ciência física que trabalha com tais entidades. O teísmo filosófico quer ser uma explicação para eventos perceptíveis partindo de uma entidade imperceptível. Reclama o mesmo direito da ciência que se utiliza de entidades nãosensíveis para explicar o mundo empírico. O Direito aqui é "ruim" por duas razões. A primeira é que a ciência afirma a existência de uma entidade num dado contexto teórico, mas tal entidade só é totalmente aceita como existente depois de ser observada. O segundo motivo é a diferença de status ou função das entidades físicas e de Deus. As entidades físicas servem para explicar uma parcela da realidade que para ser operada/manipulada exige a existência daquela entidade. Num contexto teórico diferente onde uma maneira mais eficaz de manipulação do real se concretize a tal entidade é descartada como se nunca tivesse "existido". Isso é bem diferente de reclamar o conceito de Deus como explicação do real tal como os teísta desejam. Mesmo que se aceite Deus como causa primeira e eficiente de tudo que existe isso não nos ajuda a operar a realidade tal qual faz a ciência. Assim o que motiva a aceitação de uma entidade inobservável na ciência é de um tipo lógico diferente da aceitação de Deus numa metodologia teísta.

Mais acima falamos das vantagens da verdade do teísmo: o desenvolvimento da ciência experimental, o enriquecimento da filosofia teórica, o direito natural, os direitos humanos, os sentimentos de solidariedade, realismo ontológico, segurança moral, responsabilidade social. Temos não somente a solução para muitos problemas filosóficos, mas inúmeros outros benefícios que nos são caros e essenciais ao nosso processo civilizatório. Se for verdade que a garantia ontológica de tudo isso está na existência de Deus, também é verdade que nada disso é garantia de sua existência e o tipo de fundacionismo platônico plasmado no teísmo contemporâneo não constitui uma epistemologia apropriada. Por essas fragilidades e por não conseguir enxergar avanços concretos no teísmo de nosso tempo para o deísmo do século XVII, não acredito que ele seja o melhor candidato para uma epistemologia da religião. E isso me leva a pesquisar outra via de fundamentação que nos afirme a possibilidade da racionalidade da religião.

Algumas coisas que sabemos são verdadeiras. Algumas dessas verdades são necessárias (não podem ser falsas) como: "se você escreve a, e, i, o, u você escreve as vogais do alfabeto". Há verdades que são contingentes (são verdadeiras, mas poderiam não ser): "a humanidade existe". Algumas verdades, apesar de contingentes possuem um status seguro, exemplo, "eu existo", "eu tenho sonhos"; é logicamente impossível que eu creia nelas e que elas não sejam verdadeiras. Algumas verdades contingentes para nós são inquebráveis e outras são falseáveis. Assim dentre as coisas que sabemos temos as que são necessariamente verdadeiras, depois as verdades contingentes e 
também as verdades contingentes seguras.

Desde Platão a filosofia tende a privilegiar epistemicamente as verdades necessárias em suas diferentes formas históricas: iluminação agostiniana no medievo, cogito cartesiano e juízos sintéticos a priori de Kant na modernidade. Depois da filosofia de Quine a crença na necessidade das verdades ficou fortemente abalada e mesmo clássicos como $2+3=5$ e "penso que existo" são motivo de desconfiança. Isso não deveria ser um problema se pensarmos que a maior parte de nossas crenças são contingentes. Diante disso, por que deveríamos nos fiar num critério de verdade tão rígido como o platônico (algo é verdadeiro se sua falsidade for impossível). Seria tal critério apropriado num mundo contingente? Esse critério rígido me parece inapropriado para um mundo que foi criado (teísmo). É um critério que só faz sentido num mundo eterno. Mesmo a ciência natural empírica começou a ser feita a partir da ideia de um mundo contingente, pois um mundo eterno não comportaria as investigações empíricas que sempre nos dão verdades contingentes. Nessa linha, um fundacionismo radical tornaria infundada não apenas a crença religiosa, mas também a ciência natural.

\section{Argumentos Pragmáticos}

Mais acima afirmamos que formulamos epistemologias para a ciência porque cremos nessa atividade pela sua importância em nossas vidas. Vimos também que a universalidade dessa atividade não é tão consistente quanto se pensava no passado. $\mathrm{Na}$ verdade é mais propriamente um produto social do que epistemológico, a saber, a maneira como vivemos nos faz crer que a ciência é universal. A crença na universalidade da ciência se baseia não em qualquer epistemologia que a sustenta, mas na eficácia da ciência. Determinada teoria é aceita por "todos" até que chegue outra mais eficaz, que fará "todos" esquecerem a anterior como se nem científica fosse e se construirá um consenso sobre a nova, onde "todos" vão crer em sua universalidade. Assim o que temos é uma universalidade com prazo de validade, onde "todos" não quer dizer todos, a saber, uma universalidade pouco platônica e muito pragmática. Mesmo sendo Platão o paradigma ocidental de racionalidade forte (verdades eternas) encontramos nele rasgos de pragmatismo. Um dos primeiros argumentos pragmáticos encontra-se no Menon 86 b-c de Platão. Lá afirma Sócrates:

....por uma coisa estou disposto a lutar o tanto quanto puder em palavras e atos a saber, que seremos melhores, mais corajosos e ativos se acreditarmos em investigar o que não sabemos do que se acreditarmos que não há sentido investigar o que não sabemos porque nunca saberemos.

Platão defende a busca do conhecimento por um argumento pragmático, a saber, porque isso nos torna melhores. Argumentos pragmáticos são práticos e favorecem que atinjamos nossos objetivos. Se tenho um objetivo e meu argumento é favorável para atingir tal objetivo, estou justificado nessa argumentação. $O$ critério do discurso não é um critério alheio vindo de fora da argumentação, mas algo vivencial e interno à atmosfera especulativa. A validade ou legitimação do argumento é vinculada à realização do objetivo, assim o racional é a alegação favorável à nossa situação atual. Não há uma sentença em si racional, mas a racionalidade é a ela conferida. Historicamente isso se deu dessa maneira. Determinado argumento vai ganhando o status de racional conforme favorece a consecução de dado acontecimento histórico, dessa maneira o conceito de livre arbítrio, cuja origem é religiosa, é um conceito 
conveniente e tomado como racional quando é favorável que assim o seja.

Essa linha de argumentação nos leva a compromissos com o antirrealismo de Wittgenstein segundo a interpretação de Trigg:

Alguns antirrealistas gostariam de atar nossas concepções de verdade e realidade à maneira como a linguagem humana é integrada com modos particulares de ação. Esse último ponto é frequentemente ligado ao último Wittgenstein e suas ideias de formas de vida e jogos de linguagem (Trigg, p.651, 2010).

Para mim essa deve ser a saída do problema. Que não consiste em assumir um antirrealismo, até porque o antirrealismo levado às últimas consequências nos leva ao solipsismo, por outro lado, o realismo desenfreado cai no ceticismo. Mas em abrir mão da questão sobre o que seja uma proposição racional em si e pensar no que entendemos por uma proposição racional.

A justificação racional da religião numa perspectiva wittgensteiniana é abordada por Roger Trigg. Partindo da teoria do significado do pensamento do Wittgenstein tardio e da ênfase em como as palavras ou conceitos são usados e o papel que têm em suas vidas, afirma o autor:

Isso significa que ele enfatiza o papel social e público dos conceitos, assim o importante é a vida compartilhada com outros, e o sistema de pensamento ao qual pertencemos. Ou seja, é o que as pessoas coletivamente fazem com seus conceitos, e não que entidade o conceito se refere ou nomeia que confere seu significado (Trigg, p.652, 2010).

É publicamente que formamos o que cremos (isso vale tanto para a filosofia teórica quanto para a prática). $\mathrm{O}$ espírito de uma sociedade, os conhecimentos que tem estabelecidos como certos, seus valores e contravalores e mesmo os ideais que defendemos não o fazemos preocupados com as razões que os tornariam significativos para nós, mas é pela ação de defendê-los e cultivar que eles são significativos. Pouca gente contesta e se pergunta o que significa a fraternidade lema da Revolução Francesa e ideal em muitos lugares, mas ninguém a rejeita como valor a ser cultivado. Não entendemos a ciência para nela confiar, mas confiamos naqueles que dela entendem. Indignamo-nos com determinadas atitudes, apesar de não sabermos explicar bem o porquê, tudo isso forma a teia teórica e ética por onde julgaremos a correção de nossas teorias e a moralidade dos atos em sociedade. Essa teia é tecida ao longo da existência pelos diferentes grupos que nos relacionamos formando em nós uma sensibilidade que nos move numa direção ou noutra.

$\mathrm{Na}$ disputa entre realistas e antirrealistas a tese dos jogos de linguagem de Wittgenstein parece favorecer os antirrealistas e nos levar ao relativismo. Para um antirrealista forte não há qualquer realidade independente de nossa linguagem e o que chamamos de realidade não passa de uma construção linguística. $O$ antirrealista não aceita nem a tese de que podemos descobrir o real ou de que ele exista e nos seja incognoscível, contudo, se trai, pois, ao afirmar que a "realidade" é construída, nos diz algo 'real'. Por sua vez, nos adverte Trigg (p.656, 2010) que: "Um simples realismo ingênuo dificilmente pode ser mantido por qualquer religião que leve a sério a transcendência de Deus".

Para Jordan (p.425, 2010) há dois tipos de argumentos pragmáticos que têm a ver com a ação de formação de crenças. $O$ primeiro nos diz que devemos crer num argumento se aquela crença traz benefícios significativos. É o que se chama "argumento - dependente". Se a crença for verdadeira o benefício o será também, ou ainda, quanto maior o benefício maior a chance da verdade da proposição (a aposta de Pascal se 
instala aqui). O segundo grupo de argumentos são chamados de "argumentos independentes" e defendem a crença independentemente de sua verdade, desde que seu benefício seja certo (aqui se colocam os argumentos de Cleanthes personagem de Hume em seus Diálogos da Religião Natural). James em seu “A Vontade de Crer” defende, em algumas circunstâncias, ser algo moralmente ou racionalmente permissível crer numa proposição devido a seus benefícios.

Assim, argumentos pragmáticos dependentes são sensíveis à verdade, enquanto os independentes, não. A relação com a verdade dos argumentos-dependentes são tais que sua verdade e funcionalidade são estritamente ligados - são verdadeiros porque são funcionais ou, os benefícios só são obtidos se a crença for verdadeira. Em contraste, argumentos pragmáticos - independentes, ignoram a verdade e se ocupam apenas dos benefícios. Nessa direção devemos entender os argumentos - independentes como relacionados às crenças e não à verdade.

Meu ponto, não é estudar a verdade de um argumento, mas a sua racionalidade. Para mim, é racional o argumento que favorece o benefício. No Estado Democrático de Direito argumentos religiosos são racionais quando favorecem esse Estado, assim como são irracionais todos os argumentos que desfavorecem esse Estado.

Defender que o homem possui livre-arbítrio é aceito racionalmente não por conta de uma construção lógico-semântica na qual chegamos a essa conclusão, mas porque isso faz com que possa funcionar um Estado de Direito onde cada um responde por suas ações. Se poderia objetar que a defesa do determinismo (aqui entendido como o contrário do livre arbítrio) não é irracional, embora não seja aceito por grande maioria. A diferença entre elas está no que geram. Admitir que o homem é livre gera um homem autônomo e comprometido por suas ações, julgar que ele não é livre gera um homem que entende que seu destino está traçado e que, portanto, sua ação não faz diferença e ele não se responsabiliza por elas. Num nível fundamental não temos como saber se somos ou não livres, de fato. Mas do ponto de vista prático temos de fazer uma opção. Os benefícios são maiores entendendo o homem como livre e, portanto, optamos por isso há muitos séculos. Nesse caso, a razão sozinha não foi capaz de nos fazer decidir por um caminho ou por outro, mas outra coisa foi o critério decisivo, o bem.

Mas também não podemos decidir se há um bem em si, ou se o que seja o bem é uma decisão nossa. Na prática isso funciona como uma escolha, independente de o bem existir ou não, decidimos o bem que queremos. Mas será que somos livres nessa escolha? E aqui voltamos à estaca zero do problema de se somos livres ou não. A questão é indecidível em última instância. Dessa maneira decisões em termos de uma verdade última a respeito da liberdade de pensamento ou de qualquer tipo são impossíveis.

\section{A Razão Vivificante}

De nossa parte estamos aqui e precisamos continuar. Contudo, diante do quadro cético pintado acima, como agir? Talvez haja um porto mais ou menos seguro, por qualquer motivo que seja queremos prosseguir vivos (desde que eu tenha um sentido qualquer para minha vida) e aqui deve estar o critério da racionalidade, argumento racional é aquele que visa preservar a vida.

A aposta de Pascal não é uma prova da existência de Deus, mas uma recomendação de crença a partir dos ganhos que essa crença gera mostrando assim a racionalidade da crença em Deus. Pascal apela para um tipo de racionalidade que Jordan chama prudencial: 
Racionalidade aqui é entendida como um tipo de racionalidade prudencial como oposta ao que poderia se chamar racionalidade epistêmica. Racionalidade prudencial diz respeito ao interesse de alguém, enquanto que a racionalidade epistêmica é estritamente conectada à evidência. A distinção entre racionalidade prudencial e racionalidade epistêmica é a forma mais geral da distinção feita acima entre argumentos pragmáticos e argumentos direcionados pela verdade (truth - directed arguments) (JORDAN, p.427, 2010).

A ciência trata de uma racionalidade empírica (seu objeto tem de ser mostrado, evidenciado) e a filosofia de uma racionalidade pura (cuja melhor definição é negativa, não possui nada de empírico). A racionalidade científica pouco serve para as questões práticas do cotidiano em sociedade, pois o objeto de uma questão filosófica prática (Ética, Política) não pode ser mostrado (a ponto de ser medido, calculado) como acontece com os objetos referidos às ciências. Em questões práticas não há evidências empíricas no mesmo sentido da razão científica. Não tem como fazer experimentos com seres humanos em suas diversas vivências sociais. A racionalidade científica sempre acaba por incluir algo diferente da racionalidade pura, a saber, as sensibilidades empíricas. Igualar a razão à razão científica é desistir da própria filosofia. Essa redução tem por consequência uma compreensão não apenas incompleta, mas problemática do ser do homem. Falando sobre a penetração do progresso científico (biogenética, neurociência e robótica) na autocompreensão do ser pessoa enquanto agente de comunicação e ação, Habermas chama a atenção para a objetificação do homem. Afirma: "O exercício de uma perspectiva de auto-objetificação que reduz a fenômenos observáveis todo o compreensível e vivenciado fomentaria também a disposição a uma correspondente autoinstrumentalização" (Habermas, 2006, p.09).

Uma das consequências do reducionismo cientificista operado na modernidade é a compreensão do que é o homem. Quando aquilo que pode ser conhecido é aquilo que pode ser medido, a própria concepção do humano passa a ser vista segundo esse paradigma, que obstrui uma visão do homem em sua humanidade, em nome da objetividade transfiguradora do homem em objeto para si.

Nesse sentido é tarefa da filosofia apontar que tipo de racionalidade é apropriada para as questões práticas, aquelas questões que enfrentamos quando convivemos em grupos humanos. A racionalidade é expressa por argumentos que descrevem crenças. Que tipo de crenças são racionais e apropriadas para as questões práticas? Resposta: toda crença que fomente a vida. A esse tipo de racionalidade chamo razão vivificante. $\mathrm{E}$ é na prática, somente na prática, por isso é essa uma postura pragmática, que saberemos se a crença é ou não racional-vivificante.

Mais acima falamos que para Willian James estaríamos justificados em ter algumas crenças mesmo sem evidência adequada para tal crença. Porém, essa crença é limitada a uma evidência contrária a ela, ou seja, não podemos crer em algo que possua uma evidência forte de sua inverdade. John Stuart Mill afirma que a crença religiosa facilitou a aquisição da moralidade. Isso não significa que a crença religiosa (para Mill) seja racional, mas é um indício de que possa ser. Minha proposta de razão vivificante acolhe o critério de Willian James que evita absurdos cognitivos como negar uma teoria científica bem estabelecida e encontra em Mill um novo caminho para a questão de Deus. Não se trata de provar que Deus exista para atestar a racionalidade da argumentação religiosa, mas de focar no porque devemos acreditar em Deus, afinal, a dignidade humana (e todos os benefícios que os teístas reclamam) só pode ser garantida numa realidade criada por Deus.

Trata-se de legitimar/justificar uma crença/ação moralmente pelo fato dela ser favorável a um bom fím como a diminuição do sofrimento. Para o autor: 
Os pais frequentemente dizem às crianças que a remoção do band-aid não vai doer muito, com a esperança de que a dor seja reduzida. Claramente, se há um dever geral de reduzir o sofrimento, alguém seria obrigado a formar crenças ou inculcá-las nos outros se isso reduzisse o nível de dor (JORDAN, p.432, 2010).

A razão vivificante é um tipo de pragmatismo que em nada satisfaz os evidencialistas e nem tenho tal pretensão, posto que julgo o evidencialismo inapropriado para uma epistemologia da religião. Segundo Jordan alguns filósofos pensam que o evidencialismo deve ser suplementado pelo pragmatismo. Ele faz uma distinção bem interessante. Posso reproduzi-la mais ou menos assim: uma coisa é acreditar numa proposição por ser ela racional, outra coisa é acreditar na proposição por ser essa a coisa racional a se fazer. Há situações em que não temos fortes razões para acreditarmos na racionalidade de uma dada proposição, mas a atitude que temos de tomar (o que devemos fazer) nos justifica em crer que aquela proposição é racional.

Acredito que é por isso que Kant postula a existência de Deus na segunda Crítica. Para Kant, não podemos decidir racionalmente se Deus existe ou não, ou seja, a racionalidade da crença não estaria justificada por nenhuma evidência teórica e muito menos empírica. Por outro lado, diante do imperativo do dever moral, da necessidade de conciliar moralidade com felicidade, postula-se a existência de Deus, ou seja, acreditar na proposição "Deus existe" é a coisa racional a ser feita.

Para James isso diminui a distância entre racionalidade evidencial e pragmática, mas algo me diz que toda racionalidade é pragmática. Crer na racionalidade evidencial é crer em algum tipo de racionalidade em si, coisa que discordei mais acima. Advogo que mesmo o que chamamos de racionalidade evidencial não vai além de uma racionalidade pragmática bem estabelecida em nossa civilização, tal qual a razão científica. Não cremos na correção dos enunciados científicos por motivos fundamentais (metafísicos). Diferentes metafísicas buscam justificar uma física (ver Kant e o próprio Newton querendo justificar a física de Newton). Do ponto de vista teórico/filosófico teorias físicas sempre deixam um vácuo gigante (Einstein nunca aceitou a mecânica Quântica por motivos puramente filosóficos), mas apesar de tudo são aceitas em determinado momento não apenas como racionais mas, para muitos, são o próprio paradigma da racionalidade.

Poucos são os que hoje aceitam o inatismo filosófico, mas quando a ciência fala de genética que inclui características psicológicas inatas, muita gente em filosofia baixa a cabeça e aceita o argumento sem perceber que isso se trata apenas da versão científica de um argumento filosófico. A aceitabilidade da teoria científica por cientistas e não cientistas se dá por seus resultados práticos evidenciados empiricamente. São eles que tornam a teoria científica racional.

Sou partidário da ideia que a epistemologia é muito mais uma tentativa de legitimar pela via teórica um conhecimento já aceito pela pragmática de nossa vida, daí nosso conceito de razão vivificante. Aceitamos esses conhecimentos porque eles funcionam e não por outro motivo. A pergunta que se põe é: funcionam as religiões em nossas vidas? Elas tornam a vida melhor? Isso é o que, no fim das contas, conferirá racionalidade a suas crenças. Assim, a racionalidade da religião não se separa de sua função na vida pública.

\section{CONSIDERaÇões Finais}

Agora faço breves considerações acerca das implicações sociais da racionalidade religiosa. Entendo com Habermas que a sociedade contemporânea é pós-secular o que 
indica que hão de ser superadas as visões laicistas de mundo construídas na modernidade. Modernidade essa tomada de ansiosa convicção na liberdade plena da subjetividade, que acabou por degringolar no subjetivismo, donde vem a perda da própria liberdade, sintomática da racionalidade contemporânea, incapaz de nortear a vida humana. Habermas deseja enfrentar esse "derrotismo da razão" admitindo que a fé tenha um papel a exercer, seja quando concorda com o "despertar das forças morais" (RATZINGER, 2013, p.51 e 52) promovido pela religião, seja quando defende a tese (Era Axial) de que em sua gênese, filosofia e religião surgem de um tronco comum.

Nessa linha de pensamento, alicerces mais seguros são propostos através de atitudes como o se fazer justiça histórica (Hegel) de que as religiões são parte constitutiva da razão. Corolário dessa atitude é entender que ser cidadão laico é permanecer em diálogo com os potenciais religiosos que formaram nossa racionalidade e sociedade, promovendo uma fecunda "articulação hermenêutica entre razão e religião" (CONILL, 2007, p. 573).

Por aqui seguimos defendendo com Norberto Bobbio uma visão laica e não laicistas da vida e evitamos um laicismo militante-politicamente (cf. HABERMAS, 2001, p. 90) que se mostrou tão nocivo quanto o Estado não-laico.

O modo como se entende a si mesmo o Estado constitucional democrático se tem desenvolvido nos marcos de uma tradição filosófica que invoca a razão 'natural' e que, por conseguinte, se apoia unicamente em argumentos públicos que, de acordo com sua pretensão, são igualmente acessíveis a todas as pessoas. (HABERMAS, 2006, p.127)

A racionalidade moderna se mostra suficiente para fundamentar as ideias de Estado e obrigações públicas, não necessitando de qualquer incremento metafísicoreligioso, contudo reconhece que o querer conviver com o outro e o agir em prol do outro (condições indispensável para a possibilidade do Estado Democrático) não pode ser obtido por "vias legais", constituindo-se como as reais fontes pré-políticas que também são fomentadas por formas de vida religiosas.

As evidências disso são nítidas quando olhamos para a influência histórica de muitos movimentos religiosos em favor da democracia como os de Martin Luther King pelos direitos civis dos negros nos EUA, as sociais-democracias e movimentos de trabalhadores a partir da encíclica Rerum Novarum de Leão XIII na Europa, ou do papel da Igreja Católica na redemocratização do Brasil.

\section{REFERÊNCIAS}

Abraham, William. Philosophical Reflection on Revelation and Scripture. In: TALIAFERRO, Charles; DRAPER, Paul and QUINN, Philip L.: A Companion to Philosophy of Religion. Oxford: Blackwell Companions to Philosophy, 2010. p.695-701.

BESUSAN, Hilan. Alguns racionalismos e empirismos contemporâneos. In: Simon, Samuel. Filosofia e Conhecimento: das formas platônicas ao naturalismo. Brasília: Editora Universidade de Brasília, 2003. p.245 - 268.

CONILL, Jesús. Racionalización Religiosa y Ciudadanía Postsecular en Perspectiva Habermasiana. Revista: PENSAMIENTO, vol. 63, núm. 238, pp. 571-581, 2007.

HABERMAS, Jürgen. Israel o Atenas. Madrid: Trotta , 2001

HABERMAS, Jürgen. Entre Naturalismo y Religión. Barcelona: Paidós, 2006.

Jordan, Jeffrey. Pragmatic Arguments. In: TALIAFERRO, Charles; DRAPER, Paul and QUINN, Philip L.: A Companion to Philosophy of Religion. Oxford: Blackwell Companions to Philosophy, 2010. p.425-433.

MARTIN, Michel. The Verificationist Challenge. In: TALIAFERRO, Charles; DRAPER, Paul 
and QUINN, Philip L.: A Companion to Philosophy of Religion. Oxford: Blackwell Companions to Philosophy, 2010. p.458-466.

Plantinga, Alvin. Reformed Epistemology. In: TALIAFERRO, Charles; DRAPER, Paul and QUINN, Philip L.: A Companion to Philosophy of Religion. Oxford: Blackwell Companions to Philosophy, 2010. p.674-680.

186 RATZINGER, Joseph. Deus Caritas Est. São Paulo: Paulinas, 2013.

Trigg, Roger. Theological Realism and Antirealism. In: TALIAFERRO, Charles; DRAPER, Paul and QUINN, Philip L.: A Companion to Philosophy of Religion. Oxford: Blackwell Companions to Philosophy, 2010. p.651-658.

van Inwagen, Peter: Ontological Arguments. In: TALIAFERRO, Charles; DRAPER, Paul and QUINN, Philip L.: A Companion to Philosophy of Religion. Oxford: Blackwell Companions to Philosophy, 2010. p.359-367.

YANDELL, Keith E. Philosophy of Religion - A Contemporary Introduction. London and New York: Routledge, 2002. 